\section{Back pain, the usefulness (or not!) of clinical tests and your invitation to Langkawi, Malaysia in October}

\author{
Gavan White
}

As I work on this Sports Doctors Australia issue of BJSM, my home city of Perth is sundrenched as in the postcards and the Qantas advertisements. The Australian Open Tennis tournament is dominating television coverage. Amid the amazing cohort of athletes I note that many have had back problems-a topic we focus on in this issue.

\section{BACK PAIN}

Back pain and management of this is an area with varied opinions. It seems that almost every healthcare practitioner has her/his favourite or preferred methods for assessment and treatment. The management of acute back injury has a lot of research that shows little difference in benefit from a range of treatments. We are slowly, but definitely, getting high- quality research that guides us.

Unfortunately, the preferences of practitioners can be slow to change. In an article looking at trying to individualise the approach, Kieran O'Sullivan (Qatar/ Ireland) presents an excellent approach to the concept of back pain that could best suit the individual (see page 489). On the other side of the boat, Gustavo Machado (Australia) found no difference in outcome between surgery and non-surgical treatments for lumbar spinal stenosis (see page 541). Matthew Fernandez (Australia) assessed the use of acupuncture for the treatment of sciatica in this PEDro synthesis (see page 539).

Correspondence to Gavan White, Rural Clinical School, University of Western Australia, Bunbury, PO Box 1219, WA 6231, Australia; gwhite@synergysports.com.au

\section{WHICH CLINICAL TESTS WORK?}

Clinical tests to make a diagnosis have come under a lot of fire with many examination signs coming up poorly as predictors of what we are expecting. In general, many tests are better at excluding a diagnosis than confirming it. In this issue, there is further information with a look at the accuracy of the Ottawa ankle and mid-foot rules by Paula Regina Beckenkamp (see page 504) as well as a review of shoulder examination tests by Christian Kopkow (see page 511). Netherlands' foot and angle maestro Niek van Dijk provides an excellent summary of the issues related to accurate ankle assessment (see page 485). Queensland University's Professor of Sports Physiotherapy, Bill Vicenzino gives us a great assessment of clinical tests to diagnose or exclude gluteal tendinopathy (see page 519).

\section{EXERCISE AND HEALTH}

The benefits of exercise and the risks of exercise are an ever-developing area of research. Read articles are presented on workload and risk (see page 486), exercise and the menstrual cycle (see page 487), high-intensity interval training and cardiometabolic health (see page 492) as well as biceps femoris architecture and injury risk and training response (see page 547).

\section{ORTHOPAEDICS}

Knowledge of various orthopaedic managements of fractures and dislocations can be daunting for the primary care sports doctor. There is an excellent app presented by Liam West to assist in decision making (see page 545). An excellent trial, by Dennis Den Hartog, looks at immobilisation after simple elbow dislocation (see page 531) and Jonas Bloch Thorland looks at the relationship between structural pathology and patient-reported pain and function in patients undergoing meniscal surgery (see page 525).

\section{SPORTS DOCTORS AUSTRALIA: SEE YOU IN MALAYSIA}

Sports Doctors Australia is an association that provides a collegiate association of primary care sports doctors and specialists from other fields such as emergency medicine, paediatrics. Sports Doctors Australia's community of practice includes the non-specialist doctor with an interest in sports medicine through to the fully committed sports doctor working with elite athletes and professional teams.

I welcome you to the annual Sports Medicine Australia (SMA) conference for 2017. 2016 was a bumper year for the SMA conference and plans are advanced for 2017. A unique opportunity for multidisciplinary interaction among those of us with an interest in exercise, sports injury management and of course promoting the most powerful health modality there is! The 2017 SMA National Conference will be held from the 25 October 2017 at The Westin Langkawi resort in Malaysia. There is no more lovely a place to improve your knowledge and skills in sports medicine.

Competing Interests None declared.

Provenance and peer review Commissioned; internally peer reviewed.

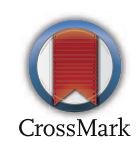

To cite White G. Br J Sports Med 2017;51:483.

Br J Sports Med 2017;51:483

doi:10.1136/bjsports-2017-097585 